en 1985 cuando Alemania y Japón fueron citados a reunirse en Nueva York para aden un 50 por ciento, facilitando la recuperación norteamericana a partir de limitado poder negociador de las restantes potencias. En definitiva, ponerle nota al riesgo de EE.UU. no pasa por examina su probabilidad de repago. EE.U. no tien nal. En cambio, puede licuar sus deudas y exportar asi buena parte de los costos de apriete de cinturón sin tener que declararse en default.

¿Qué hizo entonces Standard \&t Poor's? Reconoció, sin decirlo, ese estatus especial, y para que no se diga no hacen nada anunció una tímida advertencia usando retórica de las perspectivas negativas dos años.

Pero las agencias clasificadoras enfrentan también otros problemas. Desde luego,

no es muy fuerte el incentivo que tienen mayoritariamente del pago que perciben de los propios emisores de instrumentos somstria de clasificación de riesgo an un posición de conflicto de interés parecida a la que se develó en el corretaje de bolsa y los análisis bursátiles en EEUU. En es caso, el "acuerdo Spitzer" (bautizado en honor del competente abogado defenso público de Nueva York') comprendió compensaciones superiores a los mil millones de dolares a inversionistas perjudicados por recomendaciones sesgadas. Se probo que los analistas de diez bancos de inversión favorecian el negocio de colocación de papeles de las entidades en que trabajaban. Algo se ha modificado la normativa despues de ese caso: se han separado colocador. En el simit de las agencias ca sificadoras de riesgo, dichas murallas son de muy baja altura. Ouizás el mejor testimonio de aquello es la performance de los MBS y CDO, derivados que poco antes de valer cero en 2008 eran portadores de clasificaciones top. Como declaraba uno de los entrevistados en el documental Inside
Job, no había forma en que el volumen de instrumentos derivados aprobados con AAA pudiera haber sido ser evaluado en toda su complejildad en tan poco tiempo. Ysi una de las clasificadoras demoraba negaba, siempre estaba la del lado discliente emisor de dichos artefactos.

Con todo, regular a las clasificadoras es delicado. Los gobiernos europeos con problemas fiscales podrian querer hacerlo er remedio polrcunstancias sugieren que dad en esos casos.

¿QUÉ HACER CON LOS RATINGS Y LAS AGENCIAS?

Uno de los problemas develados en la crisis de 2008 fue la desprotección de los inversionistas más pequeños frente al cese de pagos de instrumentos que cias, aunque en calidad de las agenesos, anllos estas han preferido llamar a La legislación de un mercado financiero ma como el de los EE.UU. contempla que induzca decisiones de inversión desinformadas de sus riesgos. Curiosamente, se habian exceptuado de dicha norma las agencias calificadoras, situación que la llamada enmienda Dodd-Frank corrigió pero que algunos insisten en revertir durante ta actual discusión legislativa.

Entretanto la SEC, reguladora del mercado de valores en EE.UU., ha eximido a los emisores de ciertos instrumentos -los ABS o papeles titularizados- de publicar sus ratings como requisito previo a ofrecerlos al público. Es, sin duda, un paso importante para dejar de amparar con regulaciones medida ind las a los es. A su turno, la a buscar indicadores y metodologias complementarias para la clasificar riesgos.

Respecto de las agencias mismas, un avance sería abrir la clasificación a agencias nuevas -como ya lo están haciendo los trillonarios fondos chinos- y obligar como hace la supervisión bancaria cuan obliga a someter a pruebas de estrés los modelos internos usados para cuantificar resgos. Ninguna de las anteriores elimina del todo la ambiguedad de juicio (por e enisi, de cara a calificar el riesgo de las menos lingelanas de EE.U.), pero al Alternativamente, el riesgo de crédito deberia expresarse en el mocedo mismo. facilitar esto por ejemplo por la via de difundir profusamente los spreads de riesgo fas ayudria a complementar los juicios de agencias que al final emiten lo que ellos mismos Ilaman meras "opiniones", sin ninguna responsabilidad ulterior.

Claramente, abandonar el camino fàcil, es decir, descansar exclusivamente en clasificadores privados, demanda mayor trabajo de los reguladores. Siempre será más facil, por ejemplo, establecer equisitos de capital minimo a los intermes notios de vilores, basándose solo en 政 sabilides para proporer indicasponte se debe pensar en dotar de recursos ade. reguladores. En el caso chileno, estas sos principalmente la SVS y la Comisión Clasificadora de Riesgo. de CNN. En 2008 renunció al cargo de ras descubrirse que pagó por servicios sexuales.

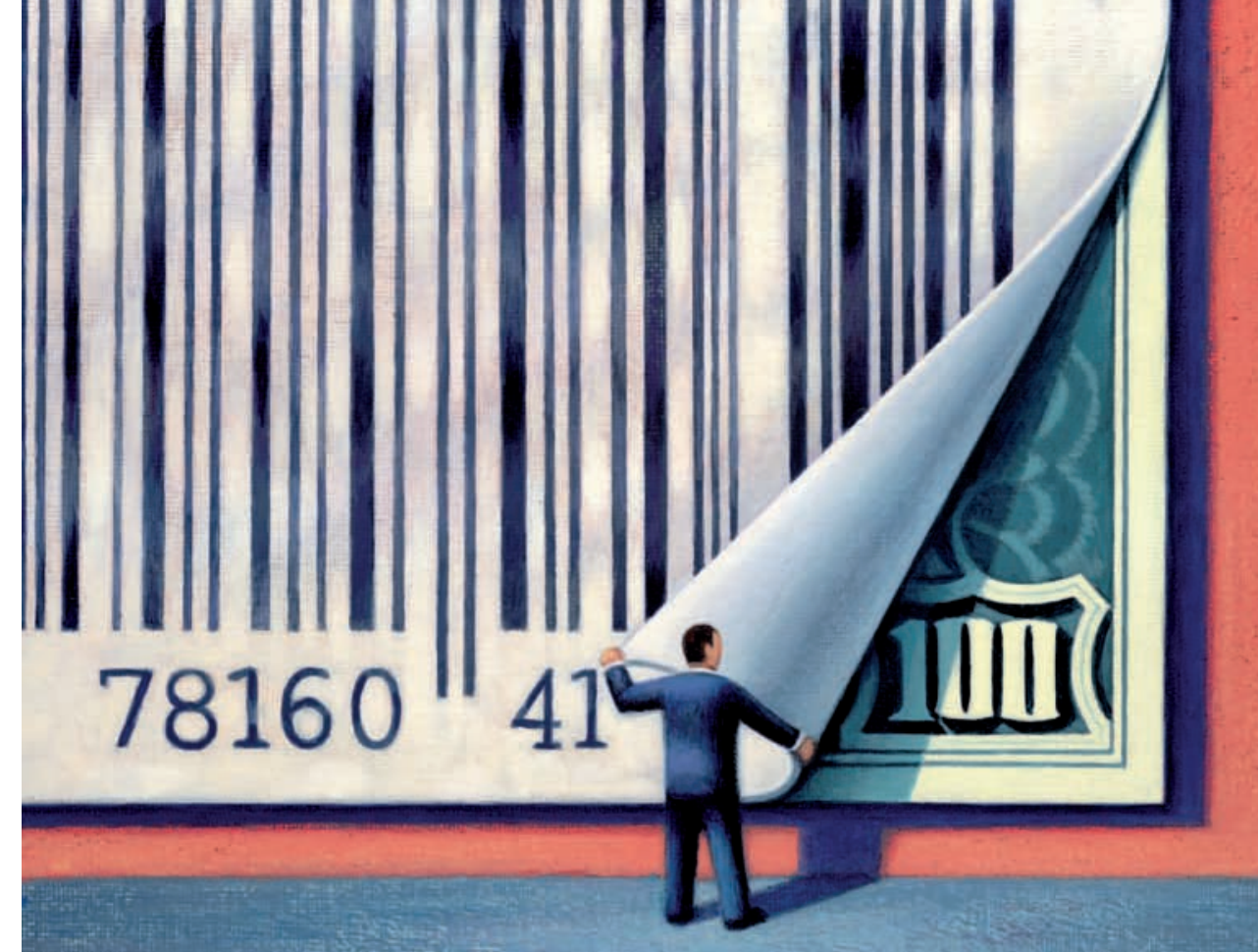

Facultad de Economia

\section{El otro costo de la energía nuclear}

\section{Por Julio Peña Torres"}

Si bien tras la tragedia de la central nuclear de Fukushima la opinión pública se ha volcado por un fuerte rechazo a esta tecnología de generación de energia, el debate nuclear no solo trata sobre el riesgo de que ocurran escapes radioactivos, la gestión de los residuos resulantes o el resgo que el das. Otro importante problema son los incentivos que tiene la industria nuclear para entregar información opaca.

Dejemos a un lado la opacidad asociada con los intereses militares y geopoliticos involucrados en desarrollar esta industria. Olvidemos también la oposición política que podria nutrirse del temor ciudadano a "peligro invisible. Aun asi, la posibilidad de que se transfieran jugosos subsidios estatales, financiados a partir del interes difuso del ciudadano de la calle, crea incentivos a no decir toda la verda.

La necesidad de importantes subsidios para la gencracion nuclear existe desde los bajo el cobijo directo del Estado. Y esto a se mantiene como una necesida vita incluso en donde se ha buscado privatizar menos parte de esta industria.

Esta es una tecnologia cara y para corredores de maratón. Un reactor de últim generación, en los actuales proyectos para EE.UU., cuesta cerca de nueve billones dólares y sus plazos de construcción pue- den tomar hasta una década, además del tiempo requerido para lograr aprobación gutorias Porias, las incertidumbres retean riesgos que un inversor privado no estará dispuesto a soportar por si solo. Las posibles caras del subsidio son múltiples. En su presupuesto para 2011, el "gsidente Obama ofreció (pre Fukushima) " billones de dólares. Otro ejemplo: en el mercado de los seguros que todo operador nuclear requiere contratar, para cubrirse ante el riesgo de accidentes que lo obliguen a entregar compensaciones, la mayoria de los paises occidentales con energia nuclear otorgan presupuesto estatal "Consondo comán de seguro (la llamada (Convención de Viena), ante la eventualidad que las compensaciones requeridas excedan la obligación legal del operador (Y)

en el área donde, por lejos, son más toris las incertezas cientificas y reguladecir, en el tratamiento y almacenaje de los residuos radioactivos que quedan una vez que el combustible nuclear completa su vida comercial, los subsidios estatales son indispensables. indesmentible que aun no existe consenso tel mundo sobre como eliminar en form "segura" y a ango plazo estos desechos de

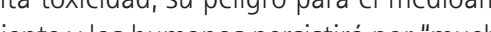
timpo". En el caso deristira por "mucho . nes. Recordemos que los primeros amepudieron haber llegado hace unos to mil años; y que el homo sapiens habrí aparecido hace unos 200 mil años.

Entonces, si de subsidios se trata, cualquier gobierno que diga que le interesa "esdiar" las posibilidades de energia nuclear, -

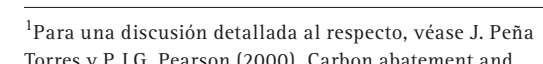

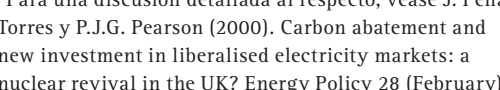

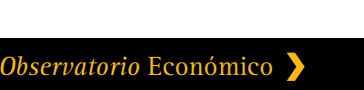
Decano: Jorge Rodriguez Grossi. e-mail: jrodrigu enomiaynegocios.uahurtado.cl/observato Periodismo UAH. 